\title{
The Challenge of Teacher-Parent Collaboration in Georgia
}

\author{
Nana Mazmishvili \\ Department of European Studies \\ Batumi Shota Rustaveli State University \\ Ninoshvili/Rustaveli 35/32, 6010 Batumi \\ Georgia \\ e-mail:nana.mazmishvili@bsu.edu.ge \\ Lela Tavdgiridze \\ Department of Pedagogical Sciences \\ Batumi Shota Rustaveli State University \\ Ninoshvili/Rustaveli 35/32, 6010 Batumi \\ Georgia \\ e-mail: lela.tavdgiridze@bsu.edu.ge \\ Dali Doborjginidze \\ Department of European Studies \\ Batumi Shota Rustaveli State University \\ Ninoshvili/Rustaveli 35/32, 6010 Batumi \\ Georgia \\ e-mail: dalidaniel@mail.ru
}

\begin{abstract}
The aim of our research is to reveal the challenges the teachers of the secondary schools of the modern world have to face in the context of being free and having enough flexibility in terms of application of contemporary teaching/learning methods while teaching foreign languages. To be more precise, teachers who follow new tendencies in teaching and try to integrate all innovative methods to ensure the communicative approach and building up the $21^{\mathrm{st}}$ century skills in learners have to defend themselves vis-à-vis parents who come with complaints on the ways the teachers teach their children expressing their concern on the quality the teaching/learning process is carried out. They have several complaints that sometimes reach the school principals too and get even more serious.

In our research we try to make classification of the complaints parents and the teachers can have in the context of relations and partnership as well as find the solution to them. The study envisages survey through the Interviews with the teachers of public as well as private schools to have the opportunity to see the differences in the approach of the parents and the teacher on top of identification of the typical complaints in general.

We attempt to elaborate the measures that could be easily implemented by the teachers to raise awareness in those who do not trust the innovative methods and create obstacles for the enthusiastic and motivated teachers. Teachers must teach instead of being tensed by thinking of the possible complications and the arguments they will need to justify themselves. On the other hand, the parents and the children sometimes may become the subject of unfair treatment as results of poorly acknowledgment of the importance of in-depth analysis of own job by the teachers not intensively involved in the special qualification raising oriented trainings, seminars and workshops.
\end{abstract}

\section{Introduction}

Relationship between the school and the parent has always been the issue of interest for many scholars since centuries (Ladson-Billings 2006). In this regard there have always been contradictory positions stated by various scholars. We consider the need of the proper education of the parents in upbringing their children to be particularly vital as they, together with the school, are responsible for ensuring the key competences and qualities in their children without which the new generation cannot contribute to building the healthy society in the contemporary world where the mankind appears to suffer from the lack of human relationship, tolerance, respect and partnership observed in every field of life (Tavdgiridze 2014).

As we consider education to be the ground of the healthy relationship and therefore, the basis for the normal social relations, we believe that the task of the teachers and the schools go far beyond what is called knowledge and skills since the "final word" and the "biggest role" in upbringing the worthy citizen belong to the education children get at schools and the education they get in their families. "Both Sources of Education" have to realize 
their role in and contribution to upbringing the person valuable for the society on the whole (Tavdgiridze and Gobronidze 2014).

Parents' involvement can have a very positive influence on the progress of a child in learning and the development in general. Moreover, parental involvement can contribute to the development of the system at the school level. As stated by Berkowitz et al. (2017) "Ascertaining parental views on key issues in school over time may help guide policies and reform statewide and within specific regions".

Moreover, as Berkowitz et al. (2017) point out: “...parents can improve a school's climate by maintaining close relationships with their children's schools and, thus, can contribute to students' school-related outcomes".

Unfortunately, the observations of the development of the parent-school relationship do not give a favourable picture today. This is particularly true in Georgia, the country which has been striving for achieving EU standards in higher education as well as follow modern approaches in the system of education in general; despite hard work of many educators in terms of taking relevant measures to improve the situation, Georgian stakeholders in the system of education have to face the "transition period" characterized with "nonuniform" situation in the education that is still in the process of trying to come out from the influence of the negative sides of the soviet education system and at the same time adjust the modern tendencies to the reality in Georgia (Kapanadze et al. 2015).

In the course of the mentioned changes in the system of education the relationship between the teachers and the parents became the subject to stagnation. Consequently, many teacher's, on the one hand, and parents, on the other hand have to face some difficulties in terms of maintaining smooth and continuous cooperation and partnership in the context of taking care of the children and providing them with the necessary knowledge, competences, skills and personal qualities. As in the most cases parents do not have the relevant pedagogical background, teachers have to take the responsibility of the coordination of the education process to ensure correct guidance based on the right didactic ground.

It is true that for the successful implementation of the education process raising parents' awareness in their as well as the teacher's role is of outmost importance and they must get some help from the teachers as well as the administration. This happens due to the fact that administration will also get true benefits from this cooperation (Rizzo and Bajovic 2016).

The world of the globalization and the dynamic development of the civilization require the specific skills and competences from the citizen to survive in the severe competitive environment and find ones place in the society that could bring him/her self-confidence, satisfaction and peace of the soul.

On top of the presented above, modern communicative lessons are aimed at building the above-mentioned skills in learners. At least the role of the school in formation of the perfect citizen equipped with human feelings, tolerance, skills of constructive criticism is clearly stated on the level of some regulatory documentation in the field of education (Torres 1998). Schools, teachers and parents together make the triangle that must ensure upbringing of the citizen who can contribute to development of the region, country and the world. This can be well ensured, as stated above, by conducting communicative lessons oriented on the students where teachers facilitate the process of learning providing more opportunity to the students in terms of creating the ground for building more confidence, independence, creativity and what is more important problem-solving skills in the students (Makhalemele and Nel 2016).

Coming out from the above mentioned and the contemporary approach to the teaching/learning process a clear change in the way the teachers used to conduct lessons years ago and are conducting now can be observed (Dignath and Büttner 2018). Although, one can easily notice this transformation of the old classical lesson, mainly dealing with reading and retelling with the biggest share of the individual work, into the student-centred modern lessons based on various strategies of interaction-pair work, group work, pyramid approach; not everyone realizes the strong sides of the second type of the approach, thus causing some problems for the teachers, followers of the non-traditional lessons.

Communication with the secondary school teachers often reveals that they often have to sort out the complains of the parents, mainly the children of the old school, who witnessed long, endless lessons where teachers played the leading role and the students had just to learn the texts and say them by heart in front of the class. In the best-case maximum, the half of the class listened but usually no one except of the teacher listened to the person retelling the text standing with her back next to the blackboard (Moles 1993).

Differently from the situation described above, contemporary teachers, are in favour of application of various interaction strategies as well as the activities that make lesson involving, effective, increase the level of motivation of the students resulting in achieving the objectives of the lesson. Even though many teachers and other stakeholders involved in the education process confirm the advantages of the modern approaches over the classical lessons, as stated above, many parents, once realizing that their children are taught differently from the way they were taught at schools, become doubtful about the competence of the teacher and "new methods" of teaching these teachers follow. As the teachers say in many cases they have to defend themselves in front of the parents and even the headmaster trying to make them understand that the knowledge of the children is not under the risk at all and they should not put the competence and experience of the teacher under the question (Cochran-Smith 1995). This 
unawareness of the parents creates extra obstacles for the teachers and the education process in general as they hamper the smooth implementation of the teaching/learning process.

As the stakeholders and people directly involved in teaching, we became interested into what extend the parents intervene, what kind of complaints they mainly have and how they can have an impact on the teachers' career, their motivation and self-confidence.

What makes the situation even more complicated is the insufficient preparation and readiness of the teachers to conduct the lessons in line with modern requirements in terms of communicative approach and competence-based orientation. It means that even though many teachers are closely following the development in the field, quite many of them still need more trainings and guidance to adopt the modern techniques fully and ensure high quality. Therefore, one of the objectives of our research is to define the level of the preparation of the teachers in delivering lessons that are oriented on building competences and providing the relevant environment for clarification of some questions that arise from any sides involved in the process of education.

Moreover, we tried to draw some recommendations on how the obvious gap in awareness can be filled and what various parties can do in order to avoid the above stated complications and make the enthusiastic and hardworking teachers pursue their career.

Finally, what made us create the presented research is the unnatural feeling towards the education in Georgia (mainly in provinces). Despite numerous measures and the changes on the legislation level targeted at improving the system of education in Georgia, the citizens stay dissatisfied with how schools provide their input as well as the way the teachers teach to their children. Parents ask for new methods and ways of teaching, however as soon as the teacher tries to deviate from any classical methods of teaching, parents start communicating their complaints to the teachers, administration of the school and the community in general.

\section{Methodology}

In order to get real data and be able to draw a proper conclusion, we applied qualitative data analysis, literature review and analysis. The data that could provide us with the real picture were obtained through the survey we carried out for two target groups that are directly involved in the process of education and who would be able to describe the situation and provide concrete examples.

The survey was targeted at the teachers of the secondary schools and the parents who were interviewed by us in the friendly and inviting environment where both sides-teachers and parents-could feel that they are not misunderstood and that they could be given some interpretations (in case of the parents) that could help them understand or feel some support in terms of dealing with the dissatisfied parents and a headmaster (in case of the teachers).

The questions prepared for the teachers were aimed at providing opportunity to obtain the data on the types of the complaints the parents can have and the ways they express them. Moreover, the aim of the interviews with the teachers was to learn about the consequences of the complaints the parents address the teachers and the administration with as well as the unpleasant situations that influence the way they teach or ruin their confidence.

The teachers were also asked about the measures they take themselves to deal with the challenges given above and if they think of any other measures that could be implemented vis-à-vis parents so that the parents cooperate with teachers rather than criticize them.

The interviews with the parents were targeted at identification of their evaluation of the way their children are taught. They were given the chance to speak openly about the positive and negative sides of the modern education, express their opinion on the way their children are taught and share their experience in terms of the response of the administration to the concrete complaint from the parent's side.

Moreover, the interviews were conducted with the public as well as the private school teachers to identify if the situation in the regard of the above mentioned is similar or different and if the administration of the private and public schools respond to the problems similarly; if having more freedom to some extend has a positive influence and provide the administration of the private school with more flexibility when making decision in terms of interference in the teaching process.

The teachers were also asked to think of the main reason of the lack of mutual cooperation and draw some recommendations on how the gaps could be filled and the issue followed up.

The first pilot interviews were conducted with three colleagues of ours working at the public ( 1 teacher) and the private ( 2 teachers) schools. In order to ensure the validity, we tried to test the recording of the interviews with them to see how they would find answering the questions we had and even more, show openness and readiness for the constructive criticism.

The pilot interviews were also taken for four parents out of whom 2 were the parents of the kids from the public and 2 -from the private schools.

Pilot interviews did not reveal specific complications in terms of the respondents' openness, readiness to cooperate and respond with the relevant answers to the questions of ours. 
The results of the interviews, obtained through recoding, were processed with the objective to find out the typical behavior pattern of the parents towards the modern education system. Moreover, one of our objectives was to identify to what extent the modern teaching/learning methods are applied in the contemporary classroom and if applied how the quality is ensured.

\section{Results}

The results of the interviews helped us have a broad and many-sided picture of the problems formulated above. It must be highlighted that, although some teachers admit there is a problem of cooperation between the teachers and the parents, many of them do not even realise that something is wrong in the context of collaboration and have even never thought about it before. This can be explained either by the fact that the second category of the teachers are not open enough to speak about the problems or they just neglect the existing truth trying not to notice anything that could ruin their peaceful routine.

The outcomes of the interviews provided us with the opportunity to see how all stakeholders assess the situation and how they understand their roles in provision of the high-quality education and manage the collaboration between the parents and the teachers.

Below we present the results of the interviews separately for the teachers and the parents as well as formulate some recommendations of the measures the implementation of which is feasible and even a responsibility of all sides involved in the upbringing of the future citizen and building a healthy society in general.

\section{- Private versus public school}

The results of the interviews conducted revealed that there is not a big difference in the ways the teachers in the private and the teachers of the secondary schools teach. In other words, the tendency of teaching innovatively can be observed to the same extend at both types of schools. Questions designed for the parents were aimed at identification of the approach to teaching/learning process besides detection of the challenges the parents have to face. As $80 \%$ of the parents, both from the private and the public schoolsdescribed, the lessons at their children's schools are conducted in a classical lesson style as it has been practising since centuries. Only for some single subjects the teacher's approach was mentioned as different from others. Based on the answers of the parents it can be concluded that this is not the school that follows the contemporary teaching/learning methods but the individual teachers who constantly work on their professional development and it is their personal preference and choice rather than the obligation the school sets for them.

Furthermore, even though private as well as the public school teachers admit that innovative teaching is of outmost important and even more, the new generation is a very complicated phenomenon to deal with and engage unless the teacher masters some innovative methods that make the lesson student-oriented, half of the teachers interviewed consider that the frequency of teacher training programmes they have to take under some circumstances go far beyond the tolerable amount. $30 \%$ of the teachers stated trainings are important for them and they really get benefit from them. The remaining $20 \%$ of the teachers show no particular attitude towards the trainings they can take free of charge under different educational programmes the national education system implements for the teachers of various subjects.

In conclusion at about $30 \%$ of the teachers interviewed (both in public and private schools) confirmed and proved they conduct communicative lessons aimed at development communicative skills in the students even though they have to face some challenges what regards the miscommunication with the parents.

\section{- Parents versus teachers}

The research was aimed to identify the parents' involvement in the process of education of their children in the local community in Batumi, Ajara Autonomous Republic. In order to get the real data the focus group included the teachers of the private as well as the public schools. The teachers were asked if the parents ever get involved in their teaching in the positive, in terms of providing any support teachers might need for the successful implementation of the lesson, way or tend to intervene in the teachers performance via complaining about the ways she/he teaches their children.

As the analysis of the results obtained from the teachers reveal, the variety of the pattern the parents get involved in the teaching process is big. As some teachers state parents, in particular those of the primary school children often are concerned with the fact that their children do not have to work a lot at home. In other words, they often approach the teacher complaining about the little amount of homework their children are given.This category of the parents ends up with approaching the school principal communicating their dissatisfaction with the teacher's performance thus, causing some problems to the teachers.

A big number of the teachers reported that parents often complain that their children are never requested by the teachers to retell the texts as they had to do in their school years; parents believe the children never will be able to learn the language properly unless they are urged to learn the texts by heart and then retell in front of the class. This can become the reason of complaint to the principal as well. 
Some teachers, especially teaching the first and the second forms say that many parents complain that there are no writing exercises at all and the lessons are limited to teaching/learning some simple speech patterns; these parents consider teaching/learning writing even in the first year of teaching/learning foreign language essential for language acquisition.

The most surprising fact we came across while interviewing the teachers was the parents request about providing their children with the transcription of the vocabulary in their native language; as they say they cannot help their children do their homework since they are not capable to read English words, therefore they request from the teachers to write transcription of every new English word with Georgian letters having no idea about potential risks of mispronunciation.

The teachers who are intensively involved in the teacher development schemes implemented by the government of Georgia and are highly advanced in conducting involving, interesting and communicative lessons often have to defend themselves from the parents who put the professionalism of the teacher under the question mark. For example, one of the teachers said that parents do not like when their children have to go to their classmate's home to work on the project for presentation; parents say it is not serious to request from the sixth form students to gather without a supervision of the parents; however, these parents say they cannot go with children as they are too busy and cannot spend their time on some "games". Moreover, we even found out and some parents, being asked for permission to go out and meet the classmates for some school task by their child, even shout at their children expressing mistrust towards the teacher's qualification and professionalism. In this case children appear to be the victims of unawareness and have to deal with unpleasant and unnecessary talks of their parents.

The results of the interviews with the parents clearly show the deficit of the sufficient knowledge in the system of education in general; majority of the parents do not really understand the role of the teachers in providing knowledge to their children. Moreover, parents can not evaluate properly the teachers' qualification a well as ability to conduct a result-oriented lesson unless they are involved in the system of education themselves. Due to the mentioned, some teachers may become the addressees of complaints from the parents caused by underestimation of the teacher's affords to conduct contemporary lessons oriented on provision of the knowledge and skills; on the other hand, parents attack their children as a result of ambiguousness about what the teacher does or what instructions she/he gives to their child/children.

The source of misunderstandings and dissatisfaction can often be assessment. This is particularly obvious when it comes to summative assessment when, in the majority of cases, children have no idea why they got low or high mark. Experience shows that generally, in most cases,complaints appear when children get low marks. Parents criticize the teacher and ask for interpretation. Facts say that out of 20 teachers 1 might have thought about the necessity of the rubrics or other criteria for the assessment. In this case teachers can defend themselves, however those 19 teachers, who give the mark without being protected with any kind of transparent tool that could help them to interpret the mark they gave to the concrete student, easily become the addressee of the attack of the parents or at least unpleasant discussions with them. On the other hand, there are also cases when parents address the teacher and ask for the ground their child got a high mark. In Georgian reality this does not happen so often, however the experience shows that the situation related to giving a high mark to the child could also be a challenge for the teachers.

The outcomes of the interviews with the teachers also demonstrated the lack of the awareness of the importance of the formative assessment. Most of the teachers did not prove the application of the formative assessment means at all due to what some parents, upon being faced with the low mark of their child, state that the children must be warned about potential of getting low mark for the summative assessment prior to finishing the semester when there is no chance to improve the situation. In other words, parents demand for formative assessment even though they speak about it with the words of an "unprofessional" who just unconsciously feel that there must be some stage in the process of learning where their children can receive professional guidance to the improvement so that they know, at any stage, where they are and have some instrument for continues selfevaluation; this gives them an opportunity for the improvement.

Besides the teachers who have no idea of the necessity and role of the formative assessment, there are some teachers that are aware of the importance of application of the formative assessment, however they have just a "superficial knowledge" about it what means they are not really able to use them timely and correctly, while formative assessment has its contribution to the progress of the student. One of the records of the interviews with the parents provides the example of the teachers' failure to apply for the method of peer assessment within the formative assessment tool. More precisely, as stated by one of the parents the teacher of her child made the class evaluate each other's home assignment without providing them with any criteria of the assessment. Inexperienced students gave marks automatically based either on their subjective preferences to any particular person in the class, or just putting low mark to somebody as a revenge for any misunderstanding they had in the past. As a result, the teacher had to defend herself against the parent who complaint for putting her child in an unfair and unprotected position against the unknowledgeable classmate who used this chance to "pay for the past". 
The above presented examples provide the valuable basis for elaboration of some recommendations for the stakeholders in the system of education. What is obvious, the tendency of modernization of the teaching/learning methods is noticeable, however the situation in terms of professional delivery of the lessons is of a various nature as the teachers' knowledge, experience and openness differ.

On top of these differences the parents' readiness to understand the modern standards and requirements also differ depending on their openness to the new approaches as well as the extent to which they are involved in the system of education and its development.

The listed circumstances give indication to the elaboration of some recommendations for the stakeholders who really can take some measures for the improvement of the situation described above. Some of the valued, to our mind, recommendations, will be presented below.

\section{- Assumption/background of the complexity and recommendations}

The in-depth analysis of the interviews revealed the gaps in several aspects of the system of education in Georgia. The fact is that Georgia, as post-soviet country, witnesses the diverse picture in terms of the generations the teachers and the parents belong to. The period and the system the teacher's generation belong to influences the way they think or perceive things and act. On top of that personal qualities also prompt the actions. Therefore, teachers who had to perform in the Soviet period still find it difficult to shift from the old, traditional to the modern, adjusted to the student's needs and interests, teaching ways. Even more, our personal involvement in the schemes of teacher development programmes gave us opportunity to observe that the teachers of the mentioned generation are not willing to change their attitude and criticize modern system stating that it only gives "superficial" knowledge to the students. This is true for the majority of the teachers from the Soviet period; however, the experience of working with them in the frame of the training programmes of the British Council proved that personal qualities and skills of flexibility and adjustment can make peoples' life easier. What we want to say, is that some teachers with the Soviet background of teaching demonstrate full readiness and ability to adjust to the modern tendencies and make maximum use of their knowledge and motivation merged with the wellacknowledged and acquired new tendencies of teaching.

The interviews with the teachers also showed the lack of the scope of the trainings, seminars or workshops targeted at not only raising awareness of the teachers on the current development and didactic approaches but contributing to development of the skills to put the knowledge into practice. The schemes the government provides are of good use, however for continues development more intensive coordination with the clear, transparent evaluation means for the readiness and openness of the teachers involved would be an important tool to maintain quality and sustainability. It is vital to do things for progress and development instead of doing them just for the sake of "purely doing" for reporting to the administration and other official authorities monitoring and observing the development in the education in Georgia.

As we found out in many cases the administration of the schools is not also sufficiently informed on the "philosophy" behind teaching in the modern environment through application of the innovative methods. As a result, quite often, when being addressed with the complaints by the parents they immediately require for clarification from the teachers as they are not informed enough to judge and provide relevant explanations to the parents.

Contrary to what is described above, some children can become the subject to ambiguity and discouragement due to inappropriately organized lesson that appears to be the "trial" to test some teaching method selected by the teacher without thoughtful approach and other related considerations. This, once again, confirms the importance of ensuring relevant qualification and capacity of the teachers as well as their readiness for constructive self-criticism. In this context strong collaboration among the teachers is a big asset. The culture of cooperation among the teachers has not yet been established as an ordinary behaviour "pattern" in Georgia, while mature people should find it very helpful to share the experiences and lessons learnt what could be of a big value in the context of teaching. This means that there is an urgent need to create a friendly environment for the colleagues so that they are not afraid of being criticized by their colleagues.

Last but not the list the interviews with the parents made us conclude that in the majority of cases, for public schools mainly, there is no cooperation between the parents and teachers, while collaboration between these stakeholders is very important for the successful future of the students. As the most of the parents interviewed stated they are not involved in the school life of their child at all. The reason is that many of them believe it is "school" that has to make decision in the course of providing education and formation of future of the child. In this context the role of the teacher is very important as she/he has to make the first step forward to approach the parent. The teacher is a "mediator" to make the parent and the school come close to each other. This could be a challenge for many of the teachers as this requires special communicative skills to deal with people with different characters and vision.

Moreover, teachers have to educate parents too in terms of providing explanations to them on the current developments in the system of education, the importance and necessity of the fair, objective assessment, 
application of the new didactics, outcomes of the activities set as a task to be done outside the classroom by their children. Teachers have to make parents become their partners working for one and the same objectives.

We believe that the establishment of the system or network of stakeholders is very important. School administration must be oriented on bringing all sides together to work on the development for the benefit for everyone and first of all-children. Since we observe this is not yet fully realised by all stakeholders they might not do their outmost to take actions in the regard of the above mentioned, we believe so called "steering group" should be established on the governmental level that will be closely following this issue until this is established as a daily behaviour pattern.

\section{Conclusions}

The research reported in this paper that was carried out by the authors was aimed at identification of the problems the teachers and parents, therefore children, face in Georgia. The objective was to describe the problems and the main causes as well as elaborate some recommendations to, at least, communicate the main findings to the stakeholders or key-decision makers that we did in other research works published in Georgian language.

Our interviews with the parents as well as the teachers revealed the necessity of strong establishment of networking culture that not just stays on the paper but is physically followed by all parties involved in education.

What is urgent is that the key decision-makers have to accelerate measures to raise awareness of the relevant community members on their responsibilities and roles and ensure sustainability of all practically applied actions via providing dedicated trainings, seminars, informative meetings and monitoring missions. Even though, Georgian Law on Education defines many aspects out of those mentioned above, the reality does not provide enough justification of the development.

\section{References}

Berkowitz R, Astor RA, Pineda S. DePedro KT, Weiss EL, Benbenshty R (2017) Parental Involvement and Perceptions of school Climate in California. Urban Education 1 (31): 4-6. doi:10.1177/004285916685764

Cochran-Smith M (1995) Uncertain allies: Understanding the boundaries of race and teaching. Harvard Educational Review 65(4):541-571. doi: 10.17763/haer.65.4.m77263886583326v

Dignath C, Büttner G (2018) Teachers' direct and indirect promotion of self-regulated learning in primary and secondary school mathematics classes-insights from video-based classroom observations and teacher interviews. Metacognition and Learning 13(2):127-157. doi: 10.1007/s11409-018-9181-x

Kapanadze M, Bolte C, Schulte T, Slovinsky E (2015) Stakeholders' views on science education-Curricular Delphi Study in Georgia. American Journal of Educational Research 3(7):897-906

Ladson-Billings G (2006) From the achievement gap to the education debt: Understanding achievement in US schools. Educational researcher 35(7):3-12. doi: 10.3102/0013189X035007003

Makhalemele T, Nel M (2016) Challenges experienced by district-based support teams in the execution of their functions in a specific South African province. International Journal of Inclusive Education 20(2):168-184. doi: $10.1080 / 13603116.2015 .1079270$

Moles OC (1993) Collaboration between schools and disadvantaged parents: Obstacles and openings. Families and schools in a pluralistic society 168:21-49.

Rizzo K, Bajovic M (2016) Moral Literacy through Two Lenses: Pre-Service Teachers' Preparation for Character Education. International Journal of teaching and learning in higher education 28(1):131-138

Tavdgiridze L (2014) Some Aspects of Teacher-Parent Cooperation. The first regional Conference "New Technologies and Approaches to Teaching" of the Teachers' House of the Education Foundation of Ajara, Batumi, Georgia, pp. 26-28

Tavdgiridze L, Gobronidze G (2014) Urgent Problems of Teaching and Upbringing, Teacher-parent Cooperation-bases for the Child's Success. V international Scientific-Methodological Conference. Kutaisi. Georgia. Conference Proceedings, pp. 65-69

Torres CA (1998) Democracy, education, and multiculturalism: Dilemmas of citizenship in a global world. Comparative Education Review 42(4):421-447. doi: 10.1086/447522 